\title{
Effects of Acute and Chronic Reboxetine Treatment on Stress-induced Monoamine Efflux in the Rat Frontal Cortex
}

\author{
Michelle E. Page, Ph.D., and Irwin Lucki, Ph.D.
}

Reboxetine is a selective noradrenergic reuptake inhibitor that displays an antidepressant profile in both animal tests and in clinical trials. The present study examined the ability of reboxetine to alter stress-induced increases in norepinephrine, serotonin and dopamine efflux in the frontal cortex in awake behaving rats. Acute systemic administration of reboxetine $(0.3-20.0 \mathrm{mg} / \mathrm{kg})$ dosedependently increased extracellular norepinephrine in the frontal cortex while having no effect on extracellular serotonin. At $20 \mathrm{mg} / \mathrm{kg}$, reboxetine also increased extracellular dopamine. Application of a 20-min tailpinch stress increased extracellular norepinephrine. This effect was greatly potentiated in rats pretreated with reboxetine. Tailpinch did not elicit increases in dopamine in saline treated animals but this stimulus increased dopamine levels following reboxetine pretreatment. Furthermore, chronic administration of reboxetine for 14 days resulted in elevated basal concentrations of extracellular norepinephrine and dopamine and a greater net increase of extracellular norepinephrine and dopamine, but not serotonin, in response to tailpinch compared with vehicle control animals. Taken together, these data support the view that the noradrenergic and dopaminergic systems are modified by reboxetine treatment and may be important factors in the mechanism of action of antidepressant compounds.

[Neuropsychopharmacology 27:237-247, 2002] (C) 2002 American College of Neuropsychopharmacology. Published by Elsevier Science Inc.
KEY WORDS: Reboxetine; Antidepressant; Monoamines; Reuptake; In vivo microdialysis; Stress

Despite widespread efforts to understand the mechanisms of action of antidepressant drugs, the requisite changes in neural function that underlie their therapeutic effects remain unclear. Much evidence exists that points to dysfunction of the norepinephrine (NE), sero-

From the Departments of Psychiatry (MEP, IL) and Pharmacology (IL), University of Pennsylvania, 538 Clinical Research Building, 415 Curie Boulevard, Philadelphia, PA 19104.

Address correspondence to: Michelle E. Page, Ph.D., Department of Neurobiology \& Anatomy, MCP Hahnemann University, 2900 Queen Lane, Philadelphia, PA 19129. Tel: (215) 991-8420; Fax: (215) 843-9082; E-mail: page@drexel.edu

Received August 20, 2001; revised January 9, 2002; accepted January 28, 2002.

Online publication: $1 / 31 / 02$ at www.acnp.org/citations/ Npp013102238. tonin (5-HT) and dopamine (DA) neurotransmitter systems in depression. For example, it is known that drugs that alter monoamine neurotransmission provide some relief of depressive symptomatology. However, the pathophysiology associated with this disorder is not clear (Heninger and Charney 1987; Ressler and Nemeroff 2000; Schildkraut 1965). Furthermore, the acute pharmacological actions of many compounds at biogenic amine transporter sites do not account for the delay in onset of therapeutic effects. A therapeutic response is typically only observed following chronic treatment regardless of the particular class of drug or mode of treatment (Blier and DeMontigny 1994). A number of studies suggest that functional changes in receptor sensitivity following antidepressant treatment are required and may account, at least in part, for the therapeutic lag observed. For example, the downregulation of a variety of receptor subtypes, including $\beta$ - and 
$\alpha$-adrenergic, $5-\mathrm{HT}_{1 \mathrm{~A}}, 5-\mathrm{HT}_{2 \mathrm{~A}}$ and NMDA receptors, have been implicated as necessary functional adaptations following chronic antidepressant administration (Blier and DeMontigny 1994).

In the past, traditional antidepressant compounds such as the tricyclics were known to increase synaptic availability of NE, and thus an emphasis on the role of $\mathrm{NE}$ in both the pathogenesis of affective disorders and in the mechanism of action of antidepressant medications has driven much of the work in this field (Frazer 2000; Schildkraut 1965). However, most tricyclic compounds are associated with a large adverse side effect profile that contributes to low compliance among patients (Frazer 2000). The advent of the selective serotonin reuptake inhibitors (SSRIs), which have a lower side-effect profile, shifted the emphasis toward a potential crucial role of serotonergic dysfunction in affective disorders. Although a reduction in side effects associated with SSRIs has contributed to their popularity, many patients remain treatment resistant. A continuing effort to identify more efficacious antidepressant compounds has led to the emergence of the selective NE reuptake inhibitors (see Brunello and Racagni 1998). Reboxetine selectively inhibits the reuptake of synaptic $\mathrm{NE}$ without any marked affinity for other receptors or transporters (Wong et al. 2000). Additionally, reboxetine has been shown to be both clinically effective and well tolerated with a lower side-effect profile than tricyclics (Burrows et al. 1998).

The present studies sought to characterize the impact of reboxetine treatment on monoaminergic neurotransmission in the rat and to determine whether this compound could modulate the release of NE elicited by a stressor. The primary action of reboxetine is to block the NE transporter and inhibit reuptake. The brain region selected for analysis was the frontal cortex, an area that is thought to play an important role in processes related to cognition, mood control, attention and motor performance (Goodwin 1997). This brain region receives a strong modulatory input from monoaminergic neurotransmitters and many affective disorders are thought to reflect disruption of the regulation of these processes (Arnsten 1997; Le Moal and Simon 1991). In addition, interactions between the monoamine systems through heteroreceptors can be influenced by antidepressants as well as stressors.

Stress has been shown to activate the monoamine systems and is often associated with the precipitation of depressive symptomatology (Anisman and Zacharko 1982; McEwen 2000). The locus coeruleus (LC) noradrenergic system is a vital component of an individual's response to stressors or challenges and provides the majority of the noradrenergic innervation of the frontal cortex. These neurons have been well characterized in awake and anesthetized animals and can be described as being sensitive to changes in the internal and exter- nal environment (Aston-Jones and Bloom 1981; Morilak et al. 1987a,b). Thus, it is generally believed that dysregulation of this system may be an important factor in the onset of anxiety or depressive characteristics (Stanford 1995).

The NE response to an acute stressor is characterized by a brief increase in extracellular NE with a return to basal levels shortly following termination of the stressor. In this study, an intermediate dose of reboxetine which elevates basal levels of NE, did not alter the response to the stressor compared with controls. In contrast, a higher dose that does not elicit greater levels of basal extracellular NE results in a prolonged, and thus greater NE response. Following chronic treatment with reboxetine a normalized response is once again achieved.

Neuroanatomical connections between the noradrenergic, serotonergic and dopaminergic systems support the hypothesis that functional interactions between these neurotransmitter systems could be an important anatomical substrate for the therapeutic actions of antidepressants (Leger and Descarries 1978; Pickel et al. 1977; Tassin 1992). Although serotonin or norepinephrine reuptake inhibitors display selectivity in vitro, they may actually alter neurotransmission of dopamine in certain brain regions when administered systemically (Tanda et al. 1994) and more importantly, could result in alterations of other neurotransmitters when administered chronically (Millan et al. 2000). In the present study, we utilized in vivo microdialysis to examine the ability of acute and chronic reboxetine to alter extracellular concentrations of NE, 5-HT and in some cases, DA in the rat frontal cortex under basal conditions and in response to presentation of an acute stressor.

\section{METHODS}

\section{Animals}

Male Sprague-Dawley rats (Charles River Laboratories, Wilmington, MA) weighing 200-250 g at the start of the experiment were housed two per cage and maintained under conditions of constant temperature $\left(22^{\circ} \mathrm{C}\right)$ on a 12:12 h light:dark cycle (lights on at 7 A.M.) with free access to food and water. Animal procedures were conducted in accordance with the guidelines published in the NIH Guide for Care and Use of Laboratory Animals and all protocols were approved by the University of Pennsylvania Institutional Animal Care and Use Committee.

\section{Surgical Procedures}

After an acclimation period of approximately one week, rats were anesthetized with Na-pentobarbital $(50 \mathrm{mg} /$ $\mathrm{kg}$, i.p.) and placed in a stereotaxic apparatus with the 
skull flat. A small burr hole was made in the skull, centered $3.2 \mathrm{~mm}$ anterior and $\pm 0.7 \mathrm{~mm}$ lateral to bregma (alternate sides). The microdialysis probe was slowly lowered $5.0 \mathrm{~mm}$ from dura into the frontal cortex (FC) and secured with skull screws and dental acrylic. The inlet of the probe was connected to a fluid swivel (Instech Laboratories, Plymouth Meeting, PA) and the rat was placed into a cylindrical plexiglass container (Instech Laboratories, Plymouth Meeting, PA) filled with bedding and food pellets. Artificial cerebrospinal fluid (aCSF: $147 \mathrm{mM} \mathrm{NaCl}, 1.7 \mathrm{mM} \mathrm{CaCl}, 0.9 \mathrm{mM} \mathrm{MgCl}$, and $4 \mathrm{mM} \mathrm{KCl}$ ) was continuously perfused through the probe at a rate of $1.5 \mu \mathrm{l} / \mathrm{min}$. by a microliter infusion pump (Instech Laboratories, Plymouth Meeting, PA) and the rat allowed to recover overnight. Approximately $18 \mathrm{~h}$ following surgery, dialysate samples were collected every $20 \mathrm{~min}$ beginning at approximately 9 A.M. At the conclusion of the experiment, rats were deeply anesthetized and green dye was infused through the probe to mark its location. The rats were decapitated and the brains removed for subsequent histological verification of probe placement. Data were discarded if the placement was outside of the FC.

\section{Dialysis Probe Construction and Calibration}

Vertical concentric microdialysis probes were utilized (for details see Abercrombie et al. 1988). Briefly, a piece of fused silica (Polymicro Technologies, Phoenix, AZ) was inserted through PE10 tubing (Clay Adams, Parsippany, New Jersey) and a semipermeable membrane of hollow cuprammonium rayon fibers with a 224- $\mu \mathrm{m}$ o.d. and 35,000 MW cutoff (C series; Terumo Corp., Somerset, NJ) was fixed over the fused silica into the PE10 tubing with epoxy. The open end of the dialysis fiber was sealed with a $0.5 \mathrm{~mm}$ epoxy plug and a region was coated with epoxy, leaving an active area $3 \mathrm{~mm}$ in length for exchange across the membrane. The in vitro recovery rate was determined by placing the probe in a beaker of aCSF containing a known concentration of $\mathrm{NE}$ standard. The concentration of NE in the perfusate was compared with the amount in the bath. Probes that did not correspond to the typical range of recovery (16$24 \%$ ) were identified and eliminated. Because the diffusion properties of neurochemicals in brain tissue are likely different from in vitro conditions, dialysate values were not corrected for the recovery of the probe.

\section{Drug Treatments and Experimental Design}

Dose Response for Reboxetine. Reboxetine methanesulfonate (Pharmacia \& Upjohn, Kalamazoo, MI) was dissolved in deionized water and administered by i.p. injection $(2 \mathrm{ml} / \mathrm{kg})$. Rats received an injection of reboxetine $(0.3,1.0,3.0$, or $10.0 \mathrm{mg} / \mathrm{kg})$ or $0.9 \%$ saline after 2 $\mathrm{h}$ of baseline sampling. The dose of reboxetine was calculated as the base weight.

\section{Acute Reboxetine and Tailpinch}

In tailpinch experiments, baseline samples were collected for two hours prior to an i.p. injection of reboxetine $(10$ or $20 \mathrm{mg} / \mathrm{kg})$ or saline. The tailpinch stress was applied $100 \mathrm{~min}$. after drug injection. Stress exposure consisted of application of an artery clamp approximately $5 \mathrm{~cm}$ from the tip of the rat's tail for $20 \mathrm{~min}$. The rat could reach the clamp and sometimes engaged in activity (i.e., chewing, pulling) directed toward removing it but was unsuccessful and usually abandoned this activity within a couple of minutes.

\section{Chronic Reboxetine and Tailpinch}

In chronic studies, reboxetine was administered via osmotic minipumps (Alza Corp, $2.0 \mu \mathrm{l} / \mathrm{hr}$ ) implanted on Day 1. The dose was calculated so that the pumps delivered $10 \mathrm{mg} / \mathrm{kg} /$ day for 14 days based on either a $300-\mathrm{g}$ or 350-g rat. The pumps were filled with $2 \mathrm{ml}$ of solution and implanted through an incision in the skin on the back and sutured in place with wound clips. Microdialysis probes were implanted on Day 13 as described above. Baseline samples were collected for two hours before application of the tailpinch stressor. In a subset of animals (see below), clonidine (Sigma, St. Louis, MO) (1 $\mu \mathrm{M}$ dissolved in aCSF) was infused through the microdialysis probe $160 \mathrm{~min}$. after the tailpinch stimulus and samples were collected for an additional hour to assess the functional status of terminal $\alpha_{2}$ autoreceptors. This dose was selected based on previous findings of autoreceptor changes following chronic stress (Nisenbaum and Abercrombie 1993). Samples were split for analysis on two separate HPLC systems (see below).

NE Quantification. The amount of NE in the dialysate samples was determined with high pressure liquid chromatography coupled to electrochemical detection (HPLC-EC). Briefly, dialysate samples $(15 \mu \mathrm{l})$ were injected onto the HPLC using an autosampler (Bioanalytical Systems, Indianapolis, IN). The HPLC consisted of an ESA solvent delivery system, a Velosep RP-18 column $(100 \times 3.2 \mathrm{~mm}, 3 \mu \mathrm{m}$; Varian Chromatography, Walnut Creek, CA). The mobile phase consisted of 60 $\mathrm{mM}$ sodium phosphate buffer $(\mathrm{pH} 4.2)$ with $100 \mu \mathrm{M}$ EDTA, $1.5 \mathrm{mM}$ sodium octyl-sulfate, and $3.5 \%(\mathrm{v} / \mathrm{v})$ methanol. The flow rate through the system was 700 $\mu \mathrm{l} / \mathrm{min}$. The detection system consisted of an ESA Coulochem II electrochemical detector with three electrodes in series; the conditioning electrode set at $+220 \mathrm{mV}$, the applied potential of the second electrode set at -150 $\mathrm{mV}$ and the compounds of interest quantified at the 
third electrode which was set at $+220 \mathrm{mV}$. Peak heights were measured and compared with the peak height of a $10^{-8} \mathrm{M}$ standard calibrated daily. The detection limit, defined as the sample amount producing a peak height that was twice the height of background noise, was 3 fmol of NE.

DA and 5-HT Quantification. The amount of DA and $5-\mathrm{HT}$ in the dialysate samples was determined with high pressure liquid chromatography coupled to electrochemical detection (HPLC-EC). Briefly, dialysate samples $(10 \mu \mathrm{l})$ were injected onto the HPLC using an autosampler (Sample Sentinel, Bioanalytical Systems; Indianapolis, IN). The HPLC consisted of a PM80 solvent delivery system, a sepstik microbore column (ODS $3 \mu \mathrm{m} ; 100 \times 1 \mathrm{~mm}$, Bioanalytical Systems, West Lafayette, IN) and the mobile phase consisted of $90 \mathrm{mM}$ sodium acetate buffer ( $\mathrm{pH} 4.2$ ) with $35 \mathrm{mM}$ citric acid, $0.34 \mathrm{mM}$ EDTA, $1.2 \mathrm{mM}$ sodium octyl-sulfate, and $10.0 \%(\mathrm{v} / \mathrm{v})$ methanol. The flow rate through the system was $110 \mu \mathrm{l} / \mathrm{min}$ and the detector was set at a potential of $+0.60 \mathrm{~V}$ relative to a $\mathrm{Ag} / \mathrm{AgCl}$ reference electrode. Data were collected on-line (Dynamax, Varian Associates; Walnut Creek, CA) for subsequent analysis. Peak heights were measured and compared with peak heights of $10^{-8} \mathrm{M}$ standards calibrated daily. The sensitivity of this assay is approximately $2 \mathrm{fmol}$ based on a twofold signal to noise ratio. The sensitivity was sufficient to measure 5-HT and DA without the addition of reuptake inhibitors to the perfusion medium.

Data Analysis. The baseline value against which drug or stress manipulation was compared was derived from the average of three samples just prior to manipulation. The neurochemical data are expressed as the mean \pm S.E.M. The overall effect of treatment with reboxetine $(0.3-20.0 \mathrm{mg} / \mathrm{kg})$ on monoamine efflux in the FC was analyzed using 2-factor ANOVAs with repeated measures over time $(p<.05)$. The absolute amount of neurotransmitter measured in dialysates (fmol/sample) was used as the dependent variable for assessment of within group effects. Basal values plus the next five samples post drug injection or tailpinch application were used in the analysis. The maximum inhibition elicited by clonidine was observed between 40 and 60 $\mathrm{min}$. after the infusion began. This value was compared with the mean of the two samples just prior to injection and the absolute change was used in a 1-way ANOVA.

\section{RESULTS}

\section{Effects of Acute Reboxetine on NE and 5-HT}

The effects of acute administration of the NE reuptake inhibitor reboxetine on extracellular NE in the frontal cortex are shown in Figure 1, panel A. An overall ANOVA revealed no significant effect of treatment
$\left(\mathrm{F}_{\text {dose }}(4,30)=1.82, p=.15\right)$ but a significant effect of time $\left(\mathrm{F}_{\text {time }}(5,150)=14.20 ; p<.0001\right)$ and a significant time by treatment interaction $\left(\mathrm{F}_{\text {int }}(20,150)=2.33, p=.002\right)$. Reboxetine $(0.3 \mathrm{mg} / \mathrm{kg})$ increased the concentration of extracellular NE in dialysates from $14.9 \pm 1.4 \mathrm{fmol} / 15 \mu \mathrm{l}$ to $24.4 \pm 4.6 \mathrm{fmol} / 15 \mu \mathrm{l}(64 \%$ increase at peak; $\mathrm{n}=5)$. Extracellular NE increased $164 \%$ above basal values from $9.2 \pm$ $1.1 \mathrm{fmol} / 15 \mu \mathrm{l}$ to $26.0 \pm 6.0 \mathrm{fmol} / 15 \mu \mathrm{l}$ in response to 1.0 $\mathrm{mg} / \mathrm{kg}$ reboxetine $(\mathrm{n}=10)$. The $10 \mathrm{mg} / \mathrm{kg}$ dose of reboxetine increased extracellular NE by $142 \%$ from $10.7 \pm 0.8$ $\mathrm{fmol} / 15 \mu \mathrm{l}$ to $25.9 \pm 0.8 \mathrm{fmol} / 15 \mu \mathrm{l}(\mathrm{n}=7)$. Likewise, the $20 \mathrm{mg} / \mathrm{kg}$ dose of reboxetine increased extracellular NE by $186 \%$ from $8.1 \pm 1.0 \mathrm{fmol} / 15 \mu \mathrm{l}$ to $23.2 \pm 3.4 \mathrm{fmol} / 15$ $\mu \mathrm{l}(\mathrm{n}=7)$.

The effects of acute administration of reboxetine on extracellular 5-HT are shown in Figure 1, panel B. Although only a slight increase is seen during the first sample immediately following the injection, an overall ANOVA revealed significant effects of treatment on extracellular 5 -HT $\left(\mathrm{F}_{\text {dose }}(3,12)=6.34, p<.01\right)$, significant effects over time $\left(\mathrm{F}_{\text {time }}(5,60)=6.60 ; p<.0001\right)$ and treatment by time interaction $\left(\mathrm{F}_{\text {int }}(15,60)=3.17 ; p<.001\right)$. The $10 \mathrm{mg} / \mathrm{kg}$ dose of reboxetine elicited a brief but significant increase in extracellular 5-HT $(\mathrm{F}(5,15)=9.3, p=.0003 ; \mathrm{n}=4$; 1-way ANOVA with repeated measures). No other dose tested elicited significant changes in extracellular 5-HT. The effects of reboxetine on extracellular DA were only examined at one dose in a separate group of animals that were also exposed to tailpinch (see below).

\section{Effects of Acute Reboxetine and Tailpinch}

Although both 10 and $20 \mathrm{mg} / \mathrm{kg}$ reboxetine increased extracellular NE to an absolute value that was similar ( $p=.7$, unpaired $t$-test), the percentage increase was greater for the $10 \mathrm{mg} / \mathrm{kg}$ group due to a lower basal value $(238 \%$ vs. $105 \%)$. However, the group treated with the higher dose $(20 \mathrm{mg} / \mathrm{kg})$ displayed a greater response ( $95 \%$ increase) to brief tailpinch challenge when compared with saline treated controls ( $54 \%$ increase) or the group that received $10 \mathrm{mg} / \mathrm{kg}$ ( $44 \%$ increase; see Figure 2, panel A). In order to reduce potential contribution of baseline value differences to the overall treatment effects, the dependent variable employed in the between-group analysis was absolute change in neurotransmitter $(\Delta \mathrm{fmol})$ for the four samples collected during and after the tailpinch relative to the baseline value (see Figure 2, panel B). Comparison of the absolute change in NE output in response to tailpinch between the two doses of reboxetine and saline revealed a significant effect of treatment $\left(\mathrm{F}_{\text {dose }}(2,24)=9.28, p<\right.$ $.002)$, time $\left(\mathrm{F}_{\text {time }}(3,72)=3.4, p<.03\right)$ and a significant interaction $\left(\mathrm{F}_{\text {int }}(6,72)=3.54, p<.01\right)$. Post hoc analysis showed significantly greater NE output at all time points for the $20 \mathrm{mg} / \mathrm{kg}$ group (Dunnett's; $p<.05$, see Figure 2, panel B). 

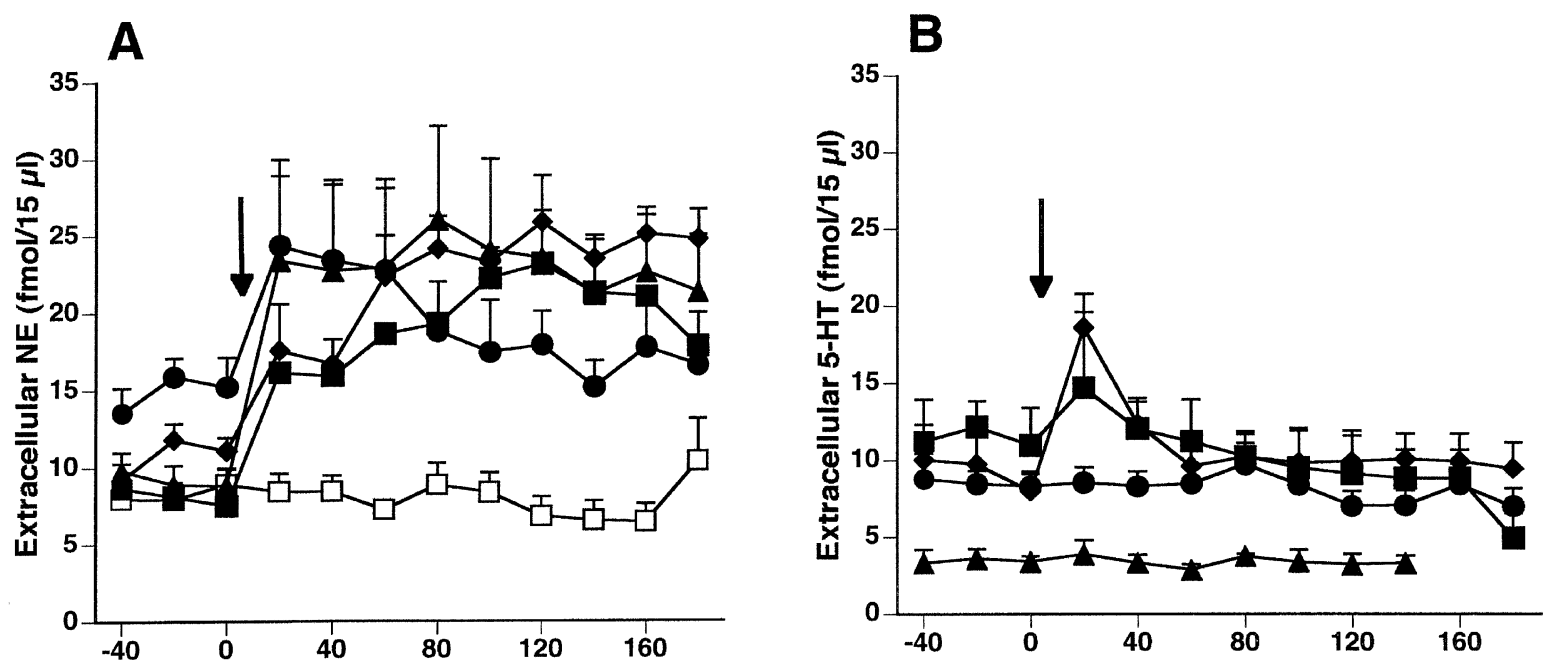

Time after injection ( $\mathrm{min})$

Figure 1. The effects of the norepinephrine selective reuptake inhibitor, reboxetine on extracellular NE and 5-HT in the rat frontal cortex were measured using in vivo microdialysis with HPLC-EC. Panel A illustrates the increase in extracellular NE observed in response to all doses tested: $0.3 \mathrm{mg} / \mathrm{kg}(\boldsymbol{\bullet}, \mathrm{n}=5$; baseline $=14.88 \pm 1.38 \mathrm{fmol} / 15 \mu \mathrm{l}) 1.0 \mathrm{mg} / \mathrm{kg}(\boldsymbol{\Lambda}, \mathrm{n}=10$; baseline $=9.18 \pm 1.08 \mathrm{fmol} / 15 \mu \mathrm{l}), 10 \mathrm{mg} / \mathrm{kg}(\bullet, \mathrm{n}=7$; baseline $=10.68 \pm 0.84 \mathrm{fmol} / 15 \mu \mathrm{l})$ and $20 \mathrm{mg} / \mathrm{kg}(\mathbf{\square}, \mathrm{n}=7 ; \mathrm{base}-$ line $=8.1 \pm 1.02 \mathrm{fmol} / 15 \mu \mathrm{l})$. Saline injection did not elicit any significant changes in extracellular $\mathrm{NE}(\square, \mathrm{n}=6 ; \mathrm{baseline}=$ $8.22 \pm 0.9 \mathrm{fmol} / 15 \mu \mathrm{l})$. Panel B shows the effect of reboxetine injection on extracellular $5-\mathrm{HT}(0.3-20 \mathrm{mg} / \mathrm{kg}$, see symbols above). Values represent the mean \pm S.E.M. (Basal values were determined from the mean of the three samples collected prior to drug administration).

\section{Effects of Chronic Reboxetine and Tailpinch}

Administration of reboxetine $(10 \mathrm{mg} / \mathrm{kg} /$ day, subcutaneous osmotic minipumps) for 14 days raised extracellular NE approximately fourfold above control values (chronic saline, osmotic minipumps) from $15.0 \pm 1.3$ $\mathrm{fmol} / 15 \mu \mathrm{l}$ to $64.7 \pm 5.6 \mathrm{fmol} / 15 \mu \mathrm{l}\left(\mathrm{F}_{\text {group }}(1,16)=72.6\right.$; $p<.0001$, see Figure 3, panel A). The mean level of reboxetine in plasma following 14-day treatment $(10 \mathrm{mg} /$ $\mathrm{kg}$ /day) was $41.4 \pm 3.7 \mathrm{ng} / \mathrm{ml}(\mathrm{n}=7)$.

Tailpinch significantly increased extracellular NE by $33 \%$, from $64.7 \pm 5.6 / 15 \mu \mathrm{l}$ to $85.8 \pm 7.3 \mathrm{fmol} / 15 \mu \mathrm{l}$ $\left(\mathrm{F}_{\text {time }}(5,45)=5.5, p<.001\right)$ in the chronic reboxetine group whereas tailpinch elicited a $41 \%$ increase in the chronic saline treated animals, from $15 \pm 1.3 \mathrm{fmol} / 15 \mu \mathrm{l}$ to $21.1 \pm 3.0 \mathrm{fmol} / 15 \mu \mathrm{l}\left(\mathrm{F}_{\text {time }}(5,35)=6.3, p<.001\right.$; see Figure 3, panel A). Comparison of the absolute change in NE output in response to tailpinch between the chronic reboxetine and chronic saline groups revealed no significant effect of group $\left(\mathrm{F}_{\text {group }}(1,16)=1.78, p=\right.$ .20) but a significant effect of time was demonstrated $\left(\mathrm{F}_{\text {time }}(3,48)=8.52, p=.0001\right)$. No significant interaction was detected $\left(\mathrm{F}_{\text {int }}(3,48)=2.04, p=.12\right)$.

\section{Effects of Reboxetine on DA}

The effects of treatment with reboxetine on extracellular DA levels in the frontal cortex are shown in Fig- ure 4 . Acute administration of reboxetine $(20 \mathrm{mg} / \mathrm{kg}$, i.p.) increased extracellular DA by $83 \%$ from $10.6 \pm$ $1.0 \mathrm{fmol} / 15 \mu \mathrm{l}$ to $19.4 \pm 2.7 \mathrm{fmol} / 15 \mu \mathrm{l}$ at peak $(\mathrm{F}(5,20)=5.3, p<.003 ; 1$-way ANOVA with repeated measures). Basal levels of DA increased by $89 \%$ after chronic administration of reboxetine. DA in the chronic reboxetine group was $20.1 \pm 3.3 \mathrm{fmol} / 15 \mu \mathrm{l}$ vs. $10.6 \pm 0.8 \mathrm{fmol} / 15 \mu \mathrm{l}$ in untreated controls $\left(\mathrm{F}_{\text {group }}(1,11)=6.92 ; p=.02\right.$; see Figure 4 , panel A). After acute administration of reboxetine, application of the tailpinch stimulus increased DA $72 \%$ above the reboxetine stimulated levels from $16.9 \pm 2.3 \mathrm{fmol} / 15$ $\mu l$ to $29.0 \pm 6.7 \mathrm{fmol} / 15 \mu \mathrm{l}\left(\mathrm{F}_{\text {time }}(5,20)=3.68, p<\right.$ .02). After chronic infusion of reboxetine, tailpinch significantly increased extracellular DA $83 \%$, from $20.1 \pm 3.3 \mathrm{fmol} / 15 \mu \mathrm{l}$ to $36.8 \pm 6.3 \mathrm{fmol} / 15 \mu \mathrm{l}$ $\left(\mathrm{F}_{\text {time }}(5,30)=16.3, p<.0001\right)$. Comparison of the $a b-$ solute change in DA output in response to tailpinch between the chronic reboxetine and acute reboxetine groups revealed a significant difference between groups $\left(\mathrm{F}_{\text {group }}(2,16)=5.71, p<.02\right)$, a significant effect of time $\left(\mathrm{F}_{\text {time }}(3,48)=14.67, p<.0001\right.$; see Figure 4) and a significant interaction $\left(\mathrm{F}_{\text {int }}(6,48)=6.91, p<\right.$ .0001). Post hoc analysis revealed significantly greater DA output during the tailpinch application in the chronic reboxetine group compared with chronic saline (Dunnett's; $p<.05$; see Figure 4, panel B). 

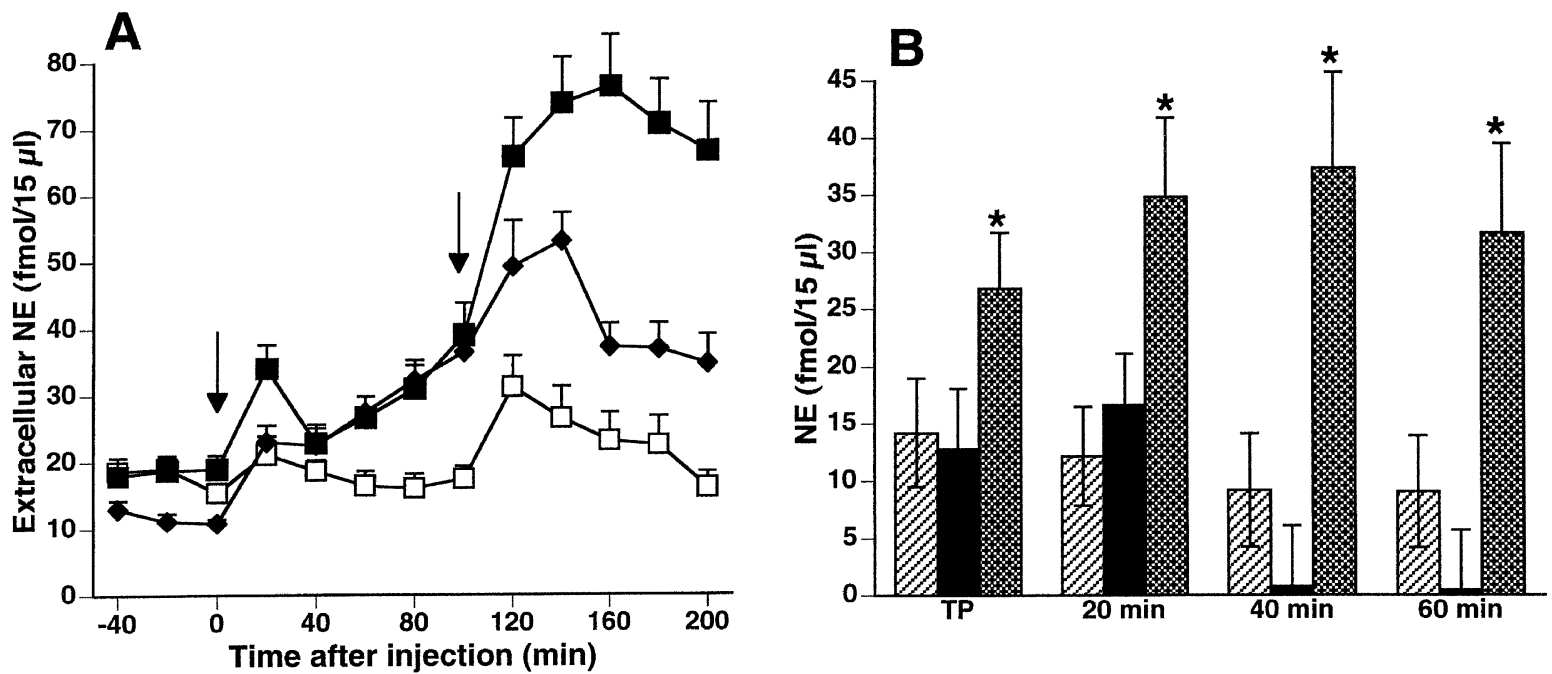

Figure 2. Panel A shows the effect of acute administration (first arrow) of reboxetine $(10 \mathrm{mg} / \mathrm{kg}, \bullet, \mathrm{n}=7 ; \mathrm{or} 20 \mathrm{mg} / \mathrm{kg}, \mathbf{\square}$, $\mathrm{n}=10)$ on extracellular NE. Saline injection $(\square, \mathrm{n}=8)$ did not increase NE. Subsequent application of a 20 min. tailpinch stress (second arrow) elicits increases in extracellular NE in all groups. The $20 \mathrm{mg} / \mathrm{kg}$ group (hatched bars on the right of each group) demonstrated a greater increase in NE than saline (striped bars) or the $10 \mathrm{mg} / \mathrm{kg}$ group (solid bars) as shown in Panel B. Absolute change in neurotransmitter output (fmol/15 $\mu \mathrm{l}$ ) is shown for the four samples immediately following application of the tailpinch. Significance is indicated by ${ }^{*}(p<.05$ compared with saline controls).

\section{Effects of Reboxetine on 5-HT}

The effects of reboxetine on extracellular 5-HT levels in the frontal cortex are shown in Figure 5. Acute administration of reboxetine $(20 \mathrm{mg} / \mathrm{kg}$, i.p.) did not alter levels of 5-HT. 5-HT levels in the chronic reboxetine group were $5.5 \pm 1.5 \mathrm{fmol} / 15 \mu \mathrm{l}$ and $4.2 \pm 1.0 \mathrm{fmol} / 15 \mu \mathrm{l}$ in untreated controls $\left(\mathrm{F}_{\text {group }}(1,9)=2.94 ; p=.12\right.$; see Figure 5 , panel A). Application of the tailpinch stimulus also had no significant effect on 5-HT after acute or chronic treatment with reboxetine (see Figure 5, panel B).

\section{Effects of Local Clonidine}

Functional changes in the sensitivity of $\alpha_{2}$ adrenergic receptors were examined in a subset of animals that received reboxetine or saline for 14 days. Local perfusion of $1 \mu \mathrm{M}$ clonidine through the microdialysis probe resulted in a $50 \%$ inhibition of extracellular NE efflux in saline control animals. The absolute change (30\% reduction) of extracellular NE in chronic reboxetine treated animals $(\mathrm{n}=8)$ from $59.4 \pm 6.6 \mathrm{fmol} / 15 \mu \mathrm{l}$ to $40.2 \pm 3.0 \mathrm{fmol} / 15 \mu \mathrm{l}$ was significantly greater compared with chronic saline treated animals $(\mathrm{n}=5)$ that showed a reduction from $11.2 \pm 3.0 \mathrm{fmol} /$ $15 \mu \mathrm{l}$ to $5.4 \pm 1.2 \mathrm{fmol} / 15 \mu \mathrm{l}\left(\mathrm{F}_{\text {group }}(1,11)=6.81, p<.05\right)$.

\section{DISCUSSION}

As would be expected from its ability to potently block the NE transporter, reboxetine dose dependently in- creases the extracellular levels of NE in the rat frontal cortex. Administration of this compound to rodents has elicited antidepressant-like behaviors in various paradigms (Harkin 1999; Connor et al. 1999; Wong et al. 2000; Cryan et al. 2002). In addition, it has been shown to be clinically effective and to improve social functioning in humans (Schatzberg 2000; Venditti et al. 2000). Our present findings are in agreement with recent reports describing increased NE in the prefrontal cortex (Invernizzi et al. 2001; Sacchetti et al. 1999) following acute and chronic reboxetine. Acute reboxetine administration produced a twofold increase in extracellular NE levels across a 60-fold range of doses in vivo. Like SSRIs (Hjorth et al. 2000), the ability of NE reuptake inhibition to increase extracellular NE may be restrained within limits maintained by adrenergic autoreceptors. In contrast, chronic administration of reboxetine produced a fourfold increase of extracellular NE levels, suggesting that adaptive changes may develop following long-term treatment that sustain higher levels of NE than can be achieved following acute injection. Desensitization of autoreceptors (Svensson and Usdin 1978) may be among the adjustments that increase net NE transmission following chronic NE reuptake inhibition.

Although reboxetine has previously been described as selective for the NE transporter (Wong et al. 2000), our findings indicate that alterations in extracellular concentrations of DA also occur in the frontal cortex following administration of reboxetine. However, the mechanism for this effect is not presently known since reboxetine demonstrates no affinity for the DA transporter. Some 

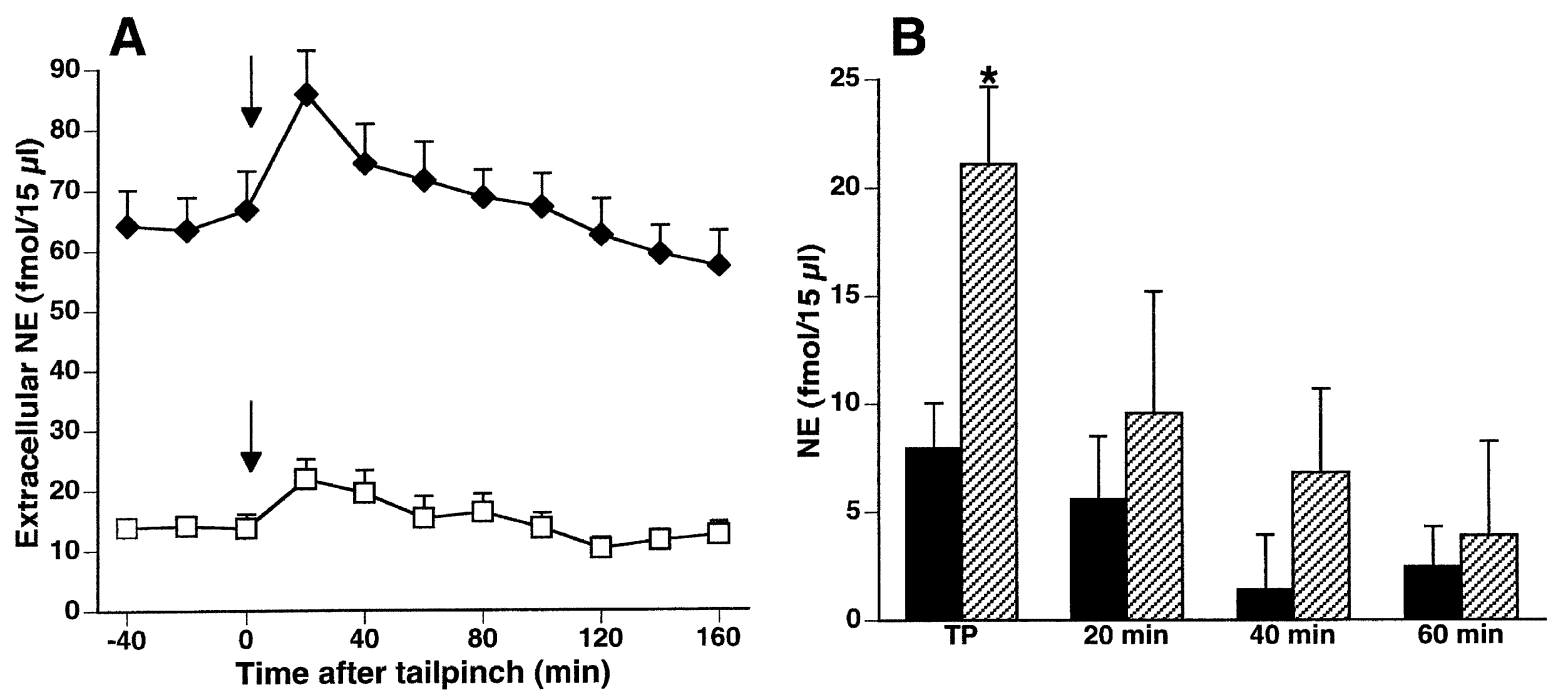

Figure 3. Chronic administration of reboxetine via subcutaneous osmotic minipumps $(10 \mathrm{mg} / \mathrm{kg} / \mathrm{day}, 14 \mathrm{days}, \bullet, \mathrm{n}=10)$ elevated basal extracellular NE levels approximately by fourfold over chronic saline treated controls $(\square, \mathrm{n}=8)$. Tailpinch (at arrows) elicited significant increases in extracellular NE in both groups (Panel A). A greater stress-induced increase in extracellular NE was observed in the chronic reboxetine group (striped bars) compared with chronic saline treated animals (solid bars) as shown in Panel B. The absolute change in neurotransmitter output (fmol/15 $\mu \mathrm{l}$ ) is shown for the four samples immediately following application of the tailpinch. Significance is indicated by ${ }^{*}(p<.05$ compared with saline controls).

evidence suggests that DA can be taken up by the NE transporter and thus may account for this effect (Carboni et al. 1990). Alternatively, this effect may be indirect, mediated through increased noradrenergic signaling at dopaminergic neurons (Linner et al. 2001). In contrast, no significant alteration in the extracellular concentration of 5-HT was observed at any dose tested.

This study provides novel evidence that the noradrenergic response to a stressor is potentiated following acute high dose reboxetine administration. Because no difference in the reboxetine stimulated level of NE was observed between the acute 10 and $20 \mathrm{mg} / \mathrm{kg}$ dose, the effect of reboxetine on stress-induced NE output may not be related to the levels of occupation of the NE transporter. After $20 \mathrm{mg} / \mathrm{kg}$ acute reboxetine, the absolute increase in NE evoked by tailpinch is greater and the response duration is significantly prolonged; a profile similar to that seen after chronic stress (Nisenbaum et al. 1991). In contrast, the chronic administration (albeit at a lower dose) of reboxetine results in a significant increase in the absolute levels of NE output elicited by tailpinch but the percentage increase above baseline is not significantly different from controls. Furthermore, this increase is restricted to only the first sample following tailpinch. This suggests that functional adaptation in the noradrenergic system after chronic treatment may restore the ability of the LC system to respond robustly to a challenge and to terminate the response with a distinct temporal resolution.

Although the experiments described above only examined the noradrenergic response to a single, some- what artificial stressor, it is well known that other stresses such as immobilization, chronic cold exposure and auditory stress also elicit increases in NE release. Due to the relative limitations on manipulating awake animals with microdialysis probes implanted in the brain, we chose to use the tailpinch stress as a simple method to assess the reactivity of noradrenergic neurons after reboxetine treatment.

As mentioned above, an exaggerated response profile has been reported in rats chronically exposed to cold when presented with an acute tailshock stimulus (Nisenbaum et al. 1991). Prolonged or repeated stress has been implicated in the precipitation of affective disorders (Abercrombie and Zigmond 1995; Charney et al. 1993; Redmond and Huang 1979). It is generally thought that response of the noradrenergic system is important to mediate stress responses but perhaps the ability to effectively terminate that response becomes compromised following chronic stress. This dysregulation of NE release could contribute to the onset of affective disorders. The long term administration of antidepressant compounds appears to induce functional changes that restore the ability of this system to respond in an appropriate manner.

Of functional relevance, activation of locus coeruleus neurons by the stress neuropeptide, corticotropin-releasing factor (CRF) elicits a prolonged increase in LC discharge and NE release in terminal regions (Page and Abercrombie 1999). It has been hypothesized that hyperactivity of CRF inputs to the LC can contribute to an 

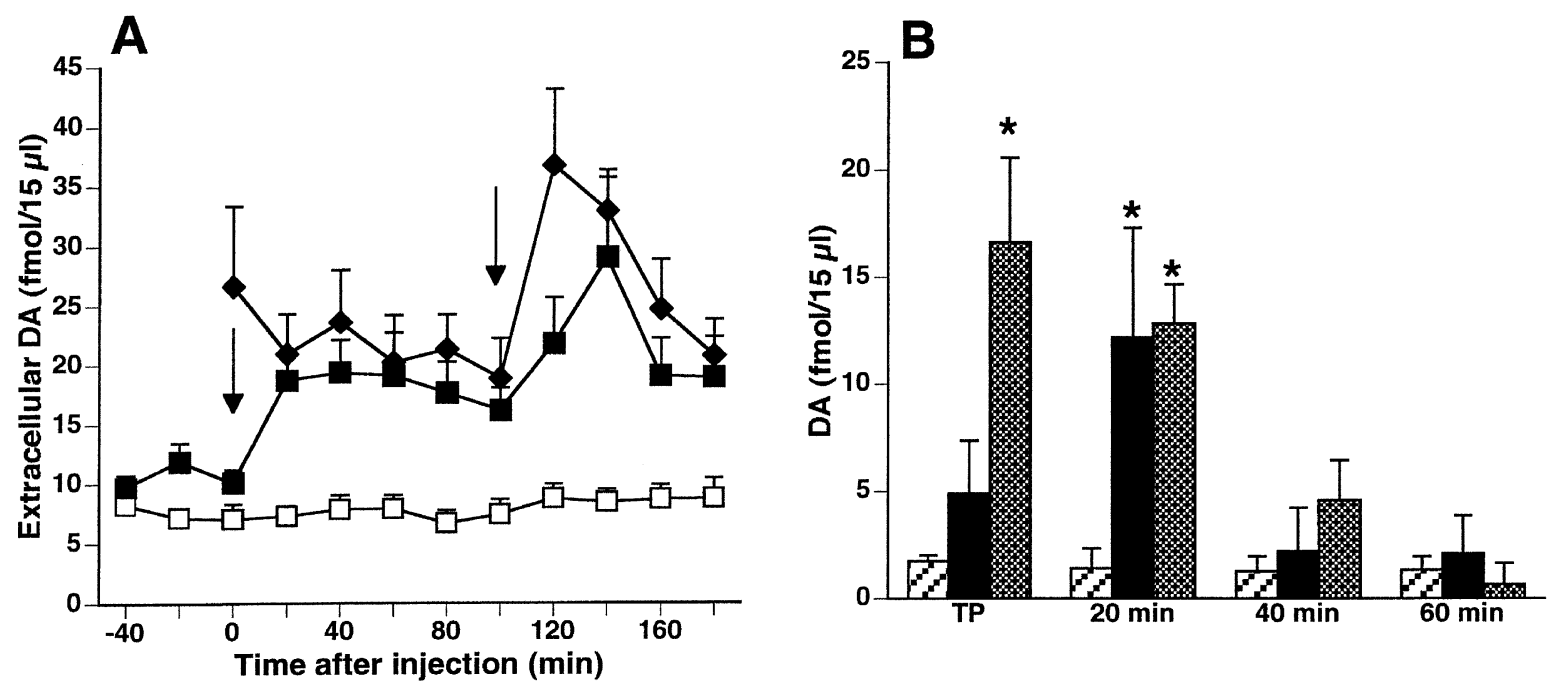

Figure 4. Acute reboxetine $(20 \mathrm{mg} / \mathrm{kg}, \mathbf{\square})$ increases extracellular DA following acute i.p. injection (first arrow). Tailpinch (second arrow) increases extracellular DA 35\% above reboxetine-stimulated basal values. Chronic reboxetine (10 mg/kg, $\diamond)$ elevated extracellular DA by the same magnitude as acute reboxetine. Saline injected controls are represented by open squares. No significant increase in DA was observed in response to tailpinch in saline injected controls. Panel B shows the greater DA response following tailpinch in chronic reboxetine treated animals in sample 1 (hatched bars on the right of each group, $\mathrm{n}=7$ ) compared with the acute reboxetine group (solid bars, $\mathrm{n}=5$ ) or chronic saline treated animals (striped bars, $n=7)$. Both acute and chronic reboxetine treated animals showed a greater response to tailpinch in the second sample.

abnormal stress response and subsequent affective disorders such as anxiety or depression (Valentino et al. 1993, 1998). This group previously demonstrated that chronic administration of desipramine (DMI) attenuates hemodynamic stress-induced activation of LC neurons but not activation by central administration of exogenous CRF (Valentino and Curtis 1991). Because this activation requires CRF release in the $\mathrm{LC}$ region, the data suggest that chronic administration of DMI results in attenuation of stress-elicited CRF release in the LC. These data are in agreement with others suggesting dysregulation of NE release as a result of chronic stress.

The ability of clonidine to reduce extracellular NE is mediated by activation of inhibitory $\alpha_{2}$ autoreceptors located on noradrenergic terminals. The absolute decrease of NE in response to clonidine after chronic administration of reboxetine provides a neuronal substrate that could be in part responsible for the long term adaptive changes that occur with chronic antidepressant treatment. Desensitization of autoreceptors is often cited as a likely factor in the delayed onset of therapeutic effects of antidepressant drugs, especially those that act via blockade of the 5-HT transporter (Pineyro and Blier 1999). Whether desensitization of $\alpha_{2}$ receptors is involved in antidepressant activity remains equivocal. However, evidence for a crucial role of $\alpha_{2}$ receptors in depression is suggested by the finding of an increased density of $\alpha_{2}$ receptors in the LC of suicide victims compared with controls (Ordway 1997). A previous study by Sacchetti et al. (1999) examined whether desensitization of $\alpha_{2}$ receptors occurred following repeated systemic injections of reboxetine but found no evidence of this. However, more recent work from this group (Invernizzi et al. 2001) demonstrated such desensitization does occur with chronic reboxetine when delivered by osmotic minipumps. The present study examined only changes in terminal $\alpha_{2}$ autoreceptor sensitivity and at only one dose. From these limited data and the acknowledged confound of analyzing absolute changes vs. percentage inhibition, it is difficult to conclusively argue for desensitization or even sensitization of $\alpha_{2}$ autoreceptors. It is clear that an alteration in the response profile of noradrenergic LC neurons does occur and a role for changes in $\alpha_{2}$ sensitivity cannot be ruled out. Further studies are warranted to understand the nature of these changes. Moreover, it is conceivable that alterations of somatodendritic autoreceptors also occur following this schedule of treatment and may contribute to the overall effects observed (Jimeniz-Rivera et al. 1996; Svensson and Usdin 1978). On the other hand, if sensitization only occurs at the terminal autoreceptors, the somatodendritic autoreceptors may underlie the termination of the response. This speculation remains to be tested. The functional implications of autoreceptor desensitization may be thought to mediate the potentiated release of NE in response to a stressor (i.e., tailpinch). The greater inhibition provided by $\alpha_{2}$ receptors allows a greater response to the stimulus without 


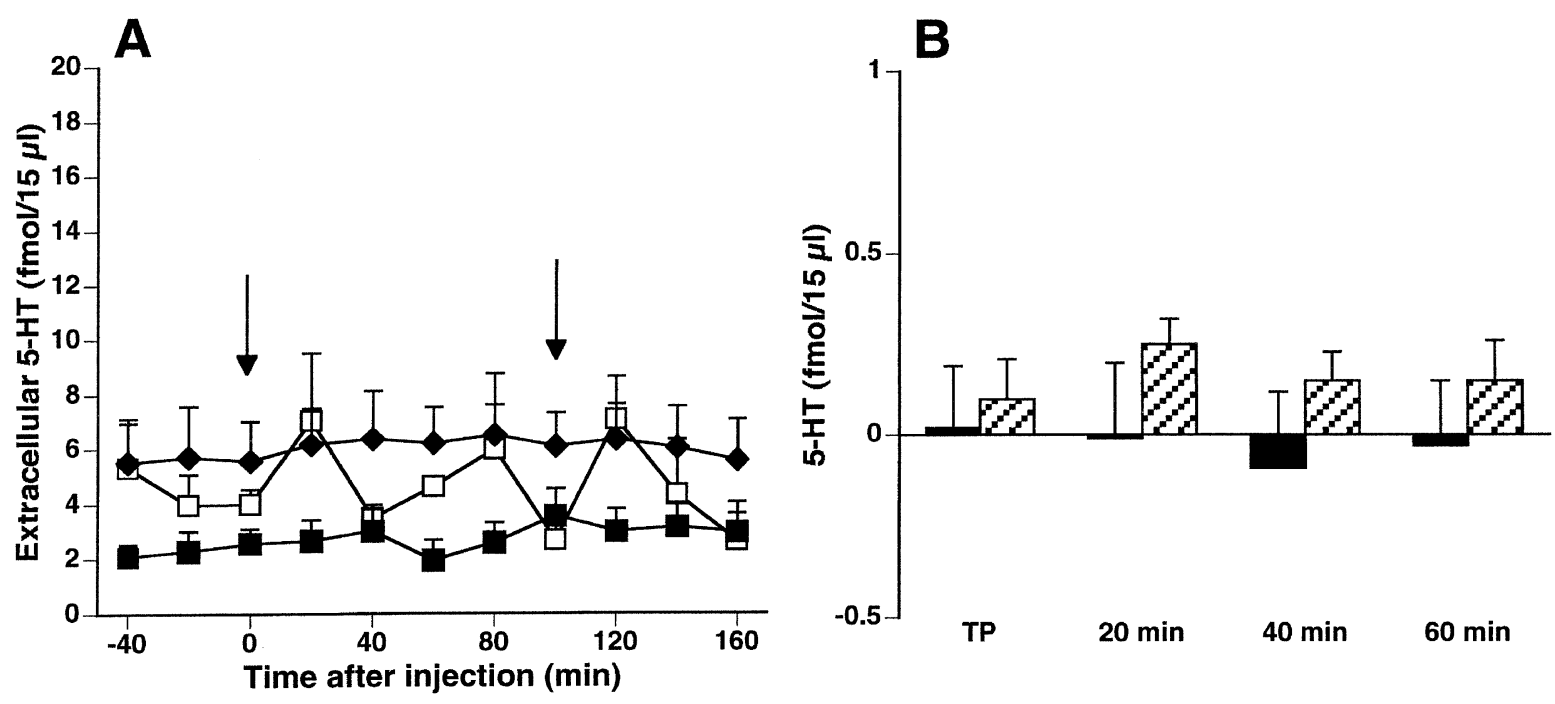

Figure 5. Acute reboxetine ( $20 \mathrm{mg} / \mathrm{kg}, \mathbf{\square} ; \mathrm{n}=5)$ did not affect extracellular 5-HT following acute i.p. injection (first arrow). Tailpinch (second arrow) did not alter extracellular 5-HT in any of the groups (saline, $\square ; \mathrm{n}=3$, and chronic reboxetine, $\bullet$; $\mathrm{n}=6$ ). Panel B illustrates the lack of effect of tailpinch on extracellular 5-HT in both acute reboxetine (solid bars) and chronic reboxetine treated animals (striped bars).

interfering with the termination of the response. A previous study by Nisenbaum and Abercrombie (1993) demonstrated that animals exposed to chronic stress displayed a leftward shift of the dose-response curve or sensitization of presynaptic $\alpha_{2}$ receptors to clonidine.

In summary, the present findings have shown that the selective noradrenergic reuptake inhibitor reboxetine increases extracellular NE and to a smaller extent, DA in the frontal cortex when administered acutely. The pattern of release that is observed in response to tailpinch following 14-day treatment with reboxetine delivered through osmotic minipumps is similar to the response to an acute challenge, though the basal levels are greatly enhanced. If we only compare the percentage increase in NE release elicited by tailpinch in animals treated with chronic reboxetine, it appears that the response is smaller. However, given greatly potentiated basal levels of NE, it is important to consider the actual amount of NE that is evoked by this stimulus. The response is characterized by a net greater increase in NE output but for a shorter duration. This response pattern may represent a more adaptive manner in which an animal responds to a challenge and may underlie some of the functional adaptations that result from long-term antidepressant treatment. The extent of increased DA efflux was equal in acute and chronic reboxetine treated animals; however, the response to the tailpinch was greater in the chronic reboxetine group when expressed as absolute change. In contrast, extracellular NE was significantly greater following chronic treatment suggesting a different mechanism underlying the changes in NE and DA elicited by reboxetine. The lack of effect on 5-HT systems is interesting given the potential interactions of the monoamine neurotransmitter systems as well as the evidence suggesting an important role of 5HT in the etiology of depression and in the efficacy of antidepressant therapy. However, it must be realized that only one discrete brain region was examined in this study and it is quite possible that functional changes occur at other sites. Furthermore, it is acknowledged that depression is not a simple disorder and it is likely that multiple brain sites and neurotransmitter systems are involved in the different subtypes of this disorder. Finally, it is also important to note that the conditions examined in the present study did not assess the ability of chronic reboxetine to reverse a deficit. In order to fully test the hypothesis that reboxetine restores the ability of the LC to respond appropriately, it would be necessary to test in an animal model that mimics signs of depression. The group of animals treated with the $20 \mathrm{mg} / \mathrm{kg}$ reboxetine that showed a potentiated NE response was surprisingly similar to chronically stressed rats and might resemble the clinical phenomenon described for panic disorder patients treated with high doses of antidepressants. This somewhat paradoxical response is similar to what has been reported for patients being treated with antidepressants for panic disorder (Ballenger 1991). There is a marked increase in the incidence of panic attacks if the patient is started out at high doses of antidepressants but this can be avoided if lower doses are used initially and the dose is titrated over the course of treatment.

However, taken together with previous findings that chronic administration of fluoxetine also results in en- 
hanced activation of LC neurons to a stressor (Page and Abercrombie 1997), our present findings suggest a possible shared mechanistic link between two distinct classes of antidepressant compounds. The exact nature of the mechanism remains unclear but it is likely to rely on the sensitivity of the noradrenergic system to stressors.

\section{ACKNOWLEDGMENTS}

This work was supported by USPHS Grant MH61418 (MEP) and a research grant from Pharmacia \& Upjohn, Kalamazoo, MI (MEP). The authors thank Dr. John Cryan for helpful discussions and Kevin Brown for technical assistance. We gratefully acknowledge the assistance of Jennifer Jannace of Triangle Laboratories for analysis of plasma reboxetine levels.

\section{REFERENCES}

Abercrombie E, Zigmond M (1995): Modification of central catecholaminergic systems by stress and injury. In Bloom F, Kupfer D (eds), Psychopharmacology. The Fourth Generation of Progress. Raven Press, New York, pp 355-361

Abercrombie ED, Keller RW, Zigmond MJ (1988): Characterization of hippocampal norepinephrine release as measured by microdialysis perfusion: pharmacological and behavioral studies. Neuroscience 27:897-904

Anisman H, Zacharko RM (1982): Depression: the predisposing influence of stress. Behav Brain Sci 5:89-137

Arnsten AFT (1997): Catecholamine regulation of the prefrontal cortex. J Psychopharmacol 11:151-162

Aston-Jones G, Bloom FE (1981): Norepinephrine-containing locus coeruleus neurons in behaving rats exhibit pronounced responses to non-noxious environmental stimuli. J Neurosci 1:887-900

Ballenger J (1991): Treatment of panic disorder and agoraphobia. In Coryell W, Winokur G (eds), The Clinical Management of Anxiety Disorders. New York: Oxford University Press

Blier P, DeMontigny C (1994): Current advances and trends in the treatment of depression. Trends Pharmacol Sci 15:220-226

Brunello N, Racagni G (1998): Rationale for the development of noradrenaline reuptake inhibitors. Hum Psychopharmacol 13:S13-S19

Burrows GD, Maguire KP, Norman TR (1998): Antidepressant efficacy and tolerability of the selective norepinephrine reuptake inhibitor reboxetine: a review. J Clin Psychiatry 59(Suppl 14):4-7

Carboni E, Tanda G, Frau R, Di Chiara G (1990): Blockade of the noradrenaline carrier increases extracellular dopamine concentrations in the prefrontal cortex: evidence that dopamine is taken up in vivo by noradrenergic terminals. J Neurochem 55:1067-1070

Charney D, Deutch A, Krystal J, Southwick S, Davis M (1993): Psychobiologic mechanisms of posttraumatic stress disorder. Arch Gen Psychiatr 50:294-305
Connor TJ, Kelliher P, Harkin A, Kelly JP, Leonard BE (1999): Reboxetine attenuates forced swim test-induced behavioural and neurochemical alterations in the rat. Eur J Pharmacol 379:125-133

Cryan J, Page M, Lucki I (2002): Noradrenergic lesions differentially alter the antidepressant-like effects of reboxetine in a modified forced swim test. Eur J Pharmacol 436:197-205

Frazer A (2000): Norepinephrine involvement in antidepressant action. J Clin Psychiatry 61(s10):25-30

Goodwin GM (1997): Neuropsychological and neuroimaging evidence for the involvement of the frontal lobes in depression. J Psychopharmacol 11:115-122

Harkin A, Kelly JP, McNamara M, Connor TJ, Dredge K, Redmond A, Leonard BE (1999): Activity and onset of action of reboxetine and effect of combination with sertraline in an animal model of depression. Eur J Pharmacol 364:123-132

Heninger GR, Charney DS (1987): Mechanism of action of antidepressant treatments: implications for the etiology and treatment of depressive disorders. In: Meltzer HY (ed), Psychopharmacology. The Third Generation of Progress. Raven Press, New York, pp 535-544

Hjorth S, Bengtsson HJ, Kullberg A, Carlzon D, Peilot H, Auerbach SB (2000): Serotonin autoreceptor function and antidepressant drug action. J Psychopharmacol 14:177-185

Invernizzi R, Parini S, Sacchetti G, Fracasso C, Caccia S, Annoni K, Samanin R (2001): Chronic treatment with reboxetine by osmotic pumps facilitates its effect on extracellular noradrenaline and may desensitize a2adrenoceptors in the prefrontal cortex. Br J Pharmacol 132:183-188

Jimeniz-Rivera CA, Segarra O, Sanacana G, Hoffman T, Savage DD, Weiss GK (1996): Chronic imipramine treatment induces downregulation of alpha-2 receptors in rat's locus coeruleus and A2 region of the tractus solitarius. Life Sci 58:287-294

Le Moal M, Simon H (1991): Mesocorticolimbic dopaminergic network: functional and regulatory roles. Physiol Rev 71:155-234

Leger L, Descarries L (1978): Serotonin nerve terminals in the locus coeruleus of adult rat: a radioautographic study. Brain Res 145:1-13

Linner L, Endersz H, Ohman D, Bengtsson F, Schalling M, Svensson T (2001): Reboxetine modulates the firing pattern of dopamine cells in the ventral tegmental area and selectively increases dopamine availability in the prefrontal cortex. J Pharmacol Exp Ther 297:540-546

McEwen BS (2000): Protective and damaging effects of stress mediators: central role of the brain. Prog Brain Res 122:25-34

Millan MJ, Lejeune F, Gobert A (2000): Reciprocal autoreceptor and heteroceptor control of serotonergic, dopaminergic and noradrenergic transmission in the frontal cortex: relevance to the actions of antidepressant agents. J Psychopharmacol 14:114-138

Morilak DA, Fornal C, Jacobs BL (1987a): Effects of physiological manipulations on locus coeruleus neuronal activity in freely moving cats. I. Thermoregulatory challenge. Brain Res 422:17-23 
Morilak DA, Fornal C, Jacobs BL (1987b): Effects of physiological manipulations on locus coeruleus neuronal activity in freely moving cats. II. Cardiovascular challenge. Brain Res 422:24-31

Nisenbaum LK, Abercrombie ED (1993): Presynaptic alterations associated with enhancement of evoked release and synthesis of norepinephrine in hippocampus of chronically cold-stressed rats. Brain Res 608:280-287

Nisenbaum LK, Zigmond MJ, Sved AF, Abercrombie ED (1991): Prior exposure to chronic stress results in enhanced synthesis and release of hippocampal norepinephrine in response to a novel stressor. J Neurosci 11:1478-1484

Ordway GA (1997): Pathophysiology of the locus coeruleus in suicide. Ann N Y Acad Sci 836:233-252

Page ME, Abercrombie ED (1997): An analysis of the effects of acute and chronic fluoxetine on extracellular norepinephrine in the rat hippocampus during stress. Neuropsychopharmacology 16:419-425

Page ME, Abercrombie ED (1999): Discrete local application of corticotropin-releasing factor increases locus coeruleus discharge and extracellular norepinephrine in rat hippocampus. Synapse 33:304-313

Pickel VM, Joh TH, Reis DJ (1977): A serotonergic innervation of noradrenergic neurons in nucleus locus coeruleus: demonstration by immunocytochemical localization of the transmitter specific enzymes tyrosine and tryptophan hydroxylase. Brain Res 131: 197-214

Pineyro G, Blier P (1999): Autoregulation of serotonin neurons: role in antidepressant drug action. Pharmacol Rev 51:533-591

Redmond DE, Huang YH (1979): New evidence for a locus coeruleus-norepinephrine connection with anxiety. Life Sci 25:2149-2162

Ressler KJ, Nemeroff CB (2000): Role of serotonergic and noradrenergic systems in the pathophysiology of depression and anxiety disorders. Depress Anxiety 12(Suppl 1):2-19

Sacchetti G, Bernini M, Bianchetti A, Parini S, Invernizzi RW, Samanin R (1999): Studies on the acute and chronic effects of reboxetine on extracellular noradrenaline and other monoamines in the rat brain. $\mathrm{Br} \mathrm{J}$ Pharmacol 128:1332-1338

Schatzberg AF (2000): Clinical efficacy of reboxetine in major depression. J Clin Psychiatry 61(Suppl 10):31-38

Schildkraut J (1965): The catecholamine hypothesis of affective disorders, a review of the supporting evidence. Am J Psychiatr 12:509-512

Stanford SC (1995): Central noradrenergic neurones and stress. Pharmac Ther 68:297-342

Svensson TH, Usdin T (1978): Feedback inhibition of brain noradrenaline neurons by tricyclic antidepressants: $\alpha$ receptor mediation. Science 202:1089-1091

Tanda G, Carboni E, Frau R, Di Chiara G (1994): Increase of extracellular dopamine in the prefrontal cortex: A trait of drugs with antidepressant potential? Psychopharmacology (Berl) 115:285-288

Tassin J (1992): NE/DA interactions in prefrontal cortex and their possible roles as neuromodulators in schizophrenia. J Neural Transm (Suppl 36):135-162

Valentino R, Curtis A (1991): Antidepressant interactions with corticotropin-releasing factor in the noradrenergic nucleus locus coeruleus. Psychopharmacol Bull 27:263-269

Valentino RJ, Curtis AL, Page ME, Pavcovich LA, FlorinLechner SM (1998): Activation of the locus ceruleus brain noradrenergic system during stress: circuitry, consequences, and regulation. Adv Pharmacol 42:781-784

Valentino RJ, Foote SL, Page ME (1993): The locus coeruleus as a site for integrating corticotropin-releasing factor and noradrenergic mediation of stress responses. Ann N Y Acad Sci 697:173-188

Venditti L, Arcelus A, Birnbaum H, Greenberg P, Barr C, Rowland C, Williamson T (2000): The impact of antidepressant use on social functioning: reboxetine versus fluoxetine. Int Clin Psychopharmacol 15:279-289

Wong E, Sonders MS, Amara S, Tinholt P, Piercey M, Hoffman W, Hyslop D, Franklin S, Porsolt R, Bonsignori A, Carfagna NM, RA (2000): Reboxetine: a pharmacologically potent, selective and specific norepinephrine reuptake inhibitor. Biol Psychiatry 47:818-829 